\title{
An exploration of parents' and young people's perspectives of hospice support
}

\author{
S. Kirk ${ }^{\star}$ and E. Pritchard $\dagger$ \\ ${ }^{\star}$ School of Nursing, Midwifery and Social Work, University of Manchester, Manchester, and \\ †Children's Nursing Research Unit, Alder Hey Children's NHS Foundation Trust, Liverpool, UK \\ Accepted for publication 9 December 2010
}

\section{Keywords}

bereavement, children, families, hospice care, mixed method, palliative care

\section{Correspondence:} Susan Kirk, PhD, MSc, BNurs, RN, RM, RHV, DN Cert, School of Nursing, Midwifery and Social Work, University of Manchester, Jean McFarlane Building, Oxford Road, Manchester M13 9PL, UK

E-mail:

sue.kirk@manchester.ac.uk

\begin{abstract}
Background Hospices are an important component of children's palliative care provision and increasing numbers of children/young people with life-limiting conditions mean that the demand placed on them for support is likely to increase. However, there has been a lack of published research examining how families experience the support provided by children's hospices. Methods The aim of the study was to investigate parents' and young people's perceptions of hospice support and identify how support could be improved. A mixed-method approach was used involving a postal survey of families and in-depth qualitative interviews with a purposively sampled subsample of parents and young people.

Results A total of 108 (49.8\% response rate) questionnaires were returned and interviews were conducted with 12 parents and seven young people. Families were highly satisfied with the support provided in terms of quality of care; interpersonal qualities of the staff; the individualized, family-focused approach; accessibility of support and involvement in decision making. Young people valued the opportunity to meet with other young people and take part in different activities. For parents the provision of a break from caring was the main way in which they were supported although they felt they wanted more of this form of support. A consistent theme in relation to support for young people and siblings was the need to develop facilities, activities and bereavement support specifically for teenagers/young people.

Conclusions Parents value a model of care that provides holistic, family-focused support that is responsive to individual needs and which promotes control and active involvement in decision making. The key challenge now is to respond to increasing need and a changing population of users.
\end{abstract}

\section{Introduction}

In the UK over the past 30 years children's palliative care has evolved from a specialist hospital-based model focused on children dying from cancer to a community-based model targeted at children with a range of life-limiting conditions (Emond \& Eaton 2004). The development of children's hospices has been instrumental in this change and hospices are now an important component of palliative care provision (Department of Health
2008). They provide a range of services, hospice and homebased breaks from caring for parents, end-of-life care, bereavement support, activities for children and siblings as well as a various therapies such as music therapy and alternative therapies. Increasing numbers of children/young people with lifelimiting conditions means that the demand placed on hospices for support is likely to increase.

A wealth of research has examined support for disabled children and young people and presented a picture of dissatisfaction 
with how services are delivered and the presence of considerable unmet need (Sloper \& Turner 1992; Beresford 1995; Middleton 1998; Sloper 1999; Kirk \& Glendinning 2004). However, there has been a lack of published research about the support provided by children's hospices. Hospices have been described as a 'lifeline' for parents, providing the type of support that they were unable to obtain from statutory providers within a home-like environment (Stein et al. 1989; Robinson \& Jackson 1999; Hunt et al. 2003). A North American study found that families felt well supported at the time of their child's death by hospice staff (Steele et al. 2005). However, other studies have been more critical, questioning the appropriateness of providing short-term care alongside end-of-life care (While et al.1996) and the potential negative impact on a young person's identity of spending parts of their childhood in a building identified by the community as being for children who are terminally ill (Morris 1998). In addition, it has been found that families may have to travel long distances to their nearest hospice and that staffing levels can at times compromise safety (Robinson \& Jackson 1999). A North American study identified the need for hospices to provide more age-appropriate activities for teenagers (Davies et al.2005).

\section{Methods}

The aim of this study was to investigate parents' and young people's perceptions of hospice support and identify how support could be improved. Specific objectives were:

1 to identify how hospices support parents, young people and siblings;

2 to assess parents', young people's and siblings' satisfaction with and views on facilities, activities and the care provided;

3 to identify how hospice support for families could be improved.

A multi-method approach was taken, comprising a postal survey and in-depth interviews. All families who had used the services of one hospice in the previous 2 years $(n=217)$ were surveyed using postal questionnaires apart from those bereaved in the previous 6 months. One questionnaire was specifically designed for bereaved families $(n=62)$ in order to assess their particular needs and remove potentially distressing questions. Questionnaire development was informed by the research objectives, a literature review and consultation with young people, parents and hospice staff. Questionnaires were piloted with four parents who provided feedback on question clarity and relevancy, completion time and presentation. The questionnaires collected data about parents' views using a mixture of closed- and open-ended questions. Some questions were adapted from those used in the Parental Needs Scale (Greco et al. 2005), the Disability Scale (Greco et al.2005) and the Measures of Processes of Care (King et al. 1995). A total of 108 completed questionnaires were returned (response rate $49.8 \%$ ) after one follow-up. Because of research governance and confidentiality issues it was not possible to assess if the characteristics of non-respondents differed from respondents. Data were analysed using $\mathrm{SPSs}^{\mathrm{TM}}$ to produce descriptive statistics. Responses to open questions were thematically analysed.

In the second stage of the study in-depth interviews were conducted with families purposefully sampled from the postal survey sample in order to obtain a more in-depth exploration of issues arising from the questionnaire analysis as well as providing an opportunity to explore issues raised by the families themselves. In families where the disabled/ill child or sibling(s) were over 8 years of age, their inclusion in the study was sought. Children with communication/cognitive impairments were included if judged by parents to be able to participate in an interview. Specific techniqies for research with children were used as appropriate (for example, photo-elicitation) to facilitate discussion. Interviews were all recorded with the participant's permission. The recordings of the interviews were transcribed and analysed to identify categories, themes and patterns using the Framework approach (Ritchie \& Lewis 2003). Interviews were jointly analysed by the authors to enhance theoretical sensitivity, uncover any biases and clarify interpretation. Because of the sensitive nature of the research, care was taken to ensure participants were not adversely affected by taking part in the study. Appropriate information sheets were developed for both parents and young people of different ages and with different cognitive abilities. Informed consent/assent was obtained from all participants at the time of the interview and assurances of anonymity and confidentiality were given apart from in relation to child protection issues.

Ethical approval for the study was obtained from the University Research Ethics Committee. Young people, parents, hospice staff and trustees were involved in planning the study and in developing information leaflets, questionnaires and topic guides. Involvement continued during the course of the study when interim findings were fed back and issues for further exploration in the interviews discussed.

\section{Results}

Findings from the quantitative and qualitative elements of the study have been integrated in order to examine how parents and young people experience hospice support. 


\section{The participants}

Questionnaires were completed by 71 parents and 37 bereaved parents. Table 1 presents the characteristics of this sample. The majority were married or living as married (although a high proportion were lone parents), had children in addition to the ill/disabled child and defined their ethnic group as White

Table 1. Characteristics of the questionnaire sample

\begin{tabular}{|c|c|c|}
\hline Characteristic & Number & Percentage \\
\hline \multicolumn{3}{|l|}{ Marital status $(n=107)$} \\
\hline Married or living as married & 73 & 68.2 \\
\hline Single & 12 & 11.2 \\
\hline Separated or divorced & 20 & 18.7 \\
\hline Widowed & 2 & 1.9 \\
\hline \multicolumn{3}{|c|}{ Presence of other children in family $(n=107)$} \\
\hline Yes & 91 & 85.1 \\
\hline No & 16 & 14.9 \\
\hline \multicolumn{3}{|c|}{ Age of ill/disabled children (years; $n=71$ ) } \\
\hline $0-5$ & 5 & 7.0 \\
\hline $6-10$ & 19 & 26.8 \\
\hline $11-15$ & 20 & 28.2 \\
\hline $16-20$ & 17 & 23.9 \\
\hline $21-25$ & 7 & 9.9 \\
\hline $26-30$ & 3 & 4.2 \\
\hline \multicolumn{3}{|l|}{ Gender of ill/disabled child $(n=71)$} \\
\hline Female & 35 & 49.3 \\
\hline Male & 36 & 50.7 \\
\hline \multicolumn{3}{|c|}{ Self-defined ethnic group status ( $n=107)$} \\
\hline White British/Irish/other & 95 & 88.8 \\
\hline Black/Black British & 0 & 0.0 \\
\hline Asian/Asian British & 7 & 6.5 \\
\hline Chinese or other ethnic group & 2 & 1.8 \\
\hline Mixed & 2 & 1.8 \\
\hline \multicolumn{3}{|c|}{ Condition/diagnosis by ICD category $(n=71)$} \\
\hline Cerebral palsy & 13 & 18.3 \\
\hline Metabolic condition & 6 & 8.5 \\
\hline Duchenne muscular dystrophy & 6 & 8.5 \\
\hline Respiratory condition & 4 & 5.6 \\
\hline Cardiovascular condition & 3 & 4.2 \\
\hline Down's syndrome & 3 & 4.2 \\
\hline Digestive system condition & 2 & 2.8 \\
\hline Brain tumour & 2 & 2.8 \\
\hline Other CNS condition & 15 & 21.1 \\
\hline Other chromosomal abnormality & 5 & 7.0 \\
\hline Other & 12 & 16.9 \\
\hline \multicolumn{3}{|l|}{ Receipt of disability living allowance } \\
\hline \multicolumn{3}{|l|}{ Care component $(n=67)$} \\
\hline Lower rate & 0 & 0.0 \\
\hline Medium rate & 5 & 7.5 \\
\hline Higher rate & 62 & 92.5 \\
\hline \multicolumn{3}{|l|}{ Mobility component $(n=64)$} \\
\hline Lower rate & 1 & 1.6 \\
\hline Higher rate & 63 & 98.4 \\
\hline None $(n=62)$ & 2 & 3.2 \\
\hline
\end{tabular}

*Data on children (e.g. age, condition) were not collected in the questionnaire sent to bereaved parents.

ICD, International Classification of Diseases; CNS, central nervous system.
British. The children/young people who used the hospice ranged in age from 2 to 30 years old (mean age 14.94, SD 7.54) but most were under 16 years old. They had a range of conditions with the most commonly reported being central nervous system conditions and cerebral palsy. Children's level of need is reflected by the finding that a considerable majority were receiving the higher rate for the care and mobility components of the disability living allowance. Interviews were conducted with 12 parents/guardians (including five bereaved parents) and seven young people aged between 9 and 22 years. We were unable to recruit any siblings to take part in the study. Characteristics of the interview sample are presented in Table 2.

\section{Support for parents}

Parents described how initially they had been apprehensive about using a hospice but any concerns had been removed once they had made a visit. Indeed, the environment in terms of facilities and its warm, caring atmosphere were important contextual factors.

The word hospice gives visions of a really sad place where children go to die, that is what I first thought and was hesitant in going there. However, what a shock we got on arrival. These children were there to live, to have the best time possible with their families and friends, no stress, no pain just fun and love in abundance. (QN2-179)

Table 2. Characteristics of the interview sample

\begin{tabular}{lcc}
\hline Characteristic & Number & Percentage \\
\hline Marital status $(n=12)$ & & \\
$\quad$ Married or living as married & 6 & 66.6 \\
$\quad$ Lone parent & 4 & 33.3 \\
Presence of other children in family $(n=12)$ & 10 & 83.3 \\
$\quad$ Yes & 2 & 16.6 \\
$\quad$ No & & \\
Age of ill/disabled children (years; $n=7)$ & 0 & 0.0 \\
$0-5$ & 2 & 28.6 \\
$6-10$ & 3 & 42.9 \\
$11-15$ & 2 & 28.6 \\
16-20 & & \\
Age of children/young people interviewed $(n=7)$ & 1 & 14.3 \\
6-10 & 2 & 28.6 \\
11-15 & 3 & 42.9 \\
16-20 & 1 & 14.3 \\
21-25 & & \\
Gender of ill/disabled children $(n=7)$ & 5 & 71.4 \\
$\quad$ Female & 2 & 28.6 \\
Male & & \\
Gender of children/young people interviewed $(n=7)$ & 3 & 42.9 \\
$\quad$ Female & 4 & 57.1 \\
Male & & \\
\hline
\end{tabular}


Table 3. Views of parents on hospice support

\begin{tabular}{|c|c|c|c|c|}
\hline & A lot of help (\%) & Some help (\%) & No help (\%) & $\begin{array}{l}\text { Not wanted, } \\
\text { needed or NA (\%) }\end{array}$ \\
\hline \multicolumn{5}{|l|}{ Support for parents } \\
\hline Getting a break from caring for your child $(n=69)$ & $48(67.6)$ & $18(25.4)$ & $1(1.4)$ & $4(5.6)$ \\
\hline Giving you time to spend with your other children $(n=70)$ & $36(51.4)$ & $15(21.4)$ & $1(1.4)$ & $18(25.7)$ \\
\hline Giving you time to spend with your partner $(n=68)$ & $34(50.0)$ & $15(22.1)$ & 0.0 & 19 (27.9) \\
\hline Someone to talk to about how you feel $(n=71)$ & $32(45.1)$ & $26(36.6)$ & $6(8.5)$ & $7(9.8)$ \\
\hline Improving your emotional health (stress, anxiety, depression; $n=67$ ) & $13(19.4)$ & $26(38.8)$ & $10(14.9)$ & $18(26.8)$ \\
\hline Improving your physical health (sleep, rest, exercise; $n=67$ ) & $11(16.4)$ & $21(31.3)$ & $11(16.4)$ & $24(35.8)$ \\
\hline Help in a crisis $(n=68)$ & $20(29.4)$ & $18(26.5)$ & $9(13.2)$ & $21(30.9)$ \\
\hline Speaking on behalf of your family when dealing with other services $(n=67)$ & $5(7.5)$ & $9(13.4)$ & $13(19.4)$ & $40(59.7)$ \\
\hline Coordinating other services $(n=65)$ & $2(3.1)$ & $8(12.3)$ & $10(14.1)$ & $45(69.2)$ \\
\hline \multicolumn{5}{|l|}{ Support for children and young people } \\
\hline The chance to have time away from the family $(n=70)$ & $38(54.3)$ & $19(27.1)$ & $3(4.3)$ & $10(12.7)$ \\
\hline The chance to take part in different activities $(n=70)$ & $34(48.6)$ & $22(31.4)$ & $3(4.3)$ & $11(25.7)$ \\
\hline The chance to go out to places such as cinemas, parks $(n=68)$ & $32(47.1)$ & $20(29.4)$ & $4(5.9)$ & $12(27.7)$ \\
\hline The chance to meet other poorly/disabled children \& young people $(n=68)$ & $23(33.8)$ & $22(32.4)$ & $3(4.4)$ & $20(29.4)$ \\
\hline Someone to talk to about their illness/condition $(n=70)$ & $18(25.4)$ & $5(7.1)$ & $5(7.1)$ & $42(60.0)$ \\
\hline The chance to meet well/non-disabled children \& young people $(n=70)$ & $16(22.9)$ & $23(32.9)$ & $5(7.1)$ & $26(37.1)$ \\
\hline \multicolumn{5}{|l|}{ Support for siblings } \\
\hline The chance to go out to places such as cinemas, parks $(n=68)$ & $17(25.0)$ & $16(23.5)$ & $16(23.5)$ & $32(47.1)$ \\
\hline The chance to take part in different activities $(n=68)$ & $17(25.0)$ & $17(25.0)$ & $17(25.0)$ & $32(47.1)$ \\
\hline The chance to meet other brothers and sisters $(n=67)$ & $16(23.9)$ & $16(23.9)$ & $1(1.5)$ & $34(50.8)$ \\
\hline Someone to talk to about their feelings $(n=67)$ & $9(13.4)$ & $9(13.4)$ & $9(13.4)$ & $9(13.4)$ \\
\hline
\end{tabular}

Table 4. Parents' confidence in hospice staff

\begin{tabular}{|c|c|c|c|c|c|}
\hline Aspect of care & Strongly agree (\%) & Agree (\%) & $\begin{array}{l}\text { Neither agree } \\
\text { nor disagree (\%) }\end{array}$ & Disagree (\%) & $\begin{array}{l}\text { Strongly } \\
\text { disagree (\%) }\end{array}$ \\
\hline $\begin{array}{l}\text { I don't worry about my child's safety while they are at the } \\
\text { hospice }(n=71)\end{array}$ & $52(73.2)$ & $17(23.9)$ & $1(1.4)$ & $1(1.4)$ & 0 \\
\hline $\begin{array}{l}\text { I have trust and confidence in the staff's ability to look after } \\
\text { my child }(n=71)\end{array}$ & $44(62.0)$ & $19(26.8)$ & $3(4.2)$ & $3(4.2)$ & $2(2.8)$ \\
\hline $\begin{array}{l}\text { I am happy with how the staff manage my child's physical } \\
\text { symptoms (e.g. pain, nausea/vomiting, seizures; } n=68 \text { ) }\end{array}$ & $37(54.4)$ & $24(35.3)$ & $5(7.4)$ & 0 & $2(2.9)$ \\
\hline $\begin{array}{l}\text { I am happy with how the staff manage my child's emotional } \\
\text { feelings (e.g. depression, anxiety, stress; } n=64 \text { ) }\end{array}$ & $33(51.6)$ & $21(32.8)$ & $6(9.4)$ & $1(1.6)$ & $3(4.7)$ \\
\hline There are always enough staff to look after my child $(n=67)$ & $31(46.3)$ & $29(43.3)$ & $3(4.5)$ & $2(3.0)$ & $2(3.0)$ \\
\hline
\end{tabular}

From the survey and interviews it appeared that the main way in which parents were supported was by having a break from caring (Table 3). Parents described how this break enabled them to spend time with their other children as well as have personal time and the opportunity to obtain some uninterrupted sleep.

I can have sometime to myself, to reflect on my life and be myself, do what I want and rest. (QN1-16)

I could switch off and not sleep with one eye open all night. I could get a good night's sleep because he is on a ventilator machine. ... your mind is always on it and you don't want to get into a deep sleep because you are worried that you might not hear it [alarm], so it is not a proper sleep that I get at night times. So when he is away

I know I can switch off. (Parent Interview 006)

It was notable that parents only felt able to have this break because of the trust and confidence they had in the staff to care for their child. They saw their child as being in 'safe hands' in the hospice - something parents had not always felt when their child had gone to other organizations for 'respite'. This finding is also reflected in the survey (Table 4). The trust parents had in the staff appeared to be based on their perception that hospice staff not only had the knowledge and skills to care for their child but also the relationships they had developed with their children and their individualized knowledge of them. 
It was reassuring when they said something isn't just right because it meant that they knew what he meant and knew his ways. (Interview Bereaved Parent 008)

However, the majority of non-bereaved families felt that the amount of support received (in terms of a break from caring) was insufficient for their needs $(41,58.6 \%, n=70)$. Many felt, although, unable to ask for more support as they were aware of the competing needs of other families.

Although the large majority of parents reported high levels of satisfaction with the hospice's quality of care $(65,95.6 \% n=68$ rated it as excellent or very good), a small number $(7,10 \%, n=$ 70) had experienced aspects of care that had given them cause for concern. In addition, a small number of parents felt that children with profound and multiple impairments could be under-stimulated and that staff found it difficult to manage children/young people with challenging behaviour. However, parents expressed feeling that they would find it difficult to raise these concerns because of their sense of gratitude for hospice support.

The hospice provided bereavement support to parents on an individual, family and group basis. For some parents this commenced prior to their child's death and was focused on preparing them for bereavement, while for others it commenced closer to the time of death. Immediately after the death many families had found using the specially equipped room at the hospice helpful to enable themselves and their extended families to spend time with their child.

We used the X Room. It just gave us somewhere to spend our last moments with her.... it helped her sisters because we could go as a family to see her more or less every day. The staff were always there. (Interview Bereaved Parent 010)

It appeared to be mainly mothers who had accessed bereavement counselling and support; indeed, many described that they had found it difficult if not impossible to encourage their partners to receive any form of emotional support. Most mothers found that counselling had helped them cope with bereavement because it provided an opportunity to talk openly about their feelings, something that was difficult to do with family members.

The reason it works with us is because you can say what you like, how you like, because believe me there's a lot of anger, there's a lot of bitterness and a lot of awfulness involved. If you're talking to family and friends they might take it personally. . . . They let you blast off and you can get all this awfulness out, before the next load builds up. ... you don't have to apologize for the way you feel.

(Interview Bereaved Parent 015)

Counselling helped parents understand their feelings and reactions to bereavement.

They help you deal with yourself. They help you cope with how you're feeling. You know you can be fine, you can be absolutely fine and then all of a sudden you'll just hit rock bottom again and you don't, had you not had that bereavement support, you wouldn't understand why you were like that and you'd be absolutely, you know, 'Why am I like this?' But because you've been, because they know exactly where you're at, they help you to understand why you feel so bad. (Interview Bereaved Parent 017)

They were also helped with how to explain the death to their other children and how to support them. Some parents found that group meetings were helpful for providing an opportunity to meet and engage in activities with other parents in the same situation. An important feature was that bereavement support was not time-limited and could be accessed by parents according to their perceived needs.

\section{Support for children and young people}

Most parents $(52,75.7 \%, n=70)$ felt that their children liked visiting the hospice and that it had provided them with the opportunity to meet other children/young people (both disabled and non-disabled), take part in activities and to have time away from their families (Table 3 ). In addition, visiting parents felt that visits helped them develop their social skills, confidence and independence. Young people described how they enjoyed the activities provided and valued the control they were given over their participation.

They put stuff on for us, but they usually leave us up to our own devices. We can choose. . . . I mean they do organize stuff but sometimes it is best to leave us to our own devices as if we have had a late night before we might not be up in time. (Young Person Interview 06)

Young people wanted to visit the hospice more frequently not only because they enjoyed the activities but also because visits were often their only contact with close friends.

It is a break and you get to see each other. With our short life expectancy we don't see each other enough. So they are really precious to me. (Young Person Interview 05) 
Both young people and parents felt that activities and facilities for young people needed to be developed. Some difficulties experienced were seen as a consequence of sharing the building with young children.

They have PlayStations and stuff but they are all kept high up in the main room. I can understand why as when the little ones are here they are pulling at the wires and things. But it just means it harder for us to get to when we want them. (Young Person Interview 03)

They have bars on the websites, you can hardly get on anything. I understand why they have locks for the younger ones but you can't access anything ... there are things we would like and would use but we can't have them because of having to think about the little ones. (Young Person Interview 06)

The solution was seen as additional facilities being built specifically for young people (and with young people's involvement in this development).

\section{Support for siblings}

Most parents felt their other children enjoyed visiting the hospice $(36,52.2 \%, n=68)$ and provided an opportunity to take part in different activities and meet other siblings (Table 3). However, disadvantages were also highlighted if siblings accompanied their disabled brother/sister on visits as they were neither then relieved of any perceived responsibilities nor did they have the opportunity to spend time alone with their parents. Younger siblings were noted to benefit more from hospice visits as activities were directed more to their age group.

The hospice played an important role in supporting bereaved siblings. This commenced in the early days after the death when parents were trying to cope with their own emotional reactions and found it difficult to support their other children.

As parents we were so engulfed in our own grief that we could not support our other children. The hospice staff were able to give them the time they needed. (QN2-124)

Many parents reported how helpful a group for bereaved siblings had been to their children in terms of helping them come to terms with their feelings and meet others in the same situation.

The group was fantastic. It allowed $\mathrm{X}$ to be with other children who were in the same boat as herself, to work through the emotions she was experiencing all in a fun environment with staff who cared. (QN2-199)

The bereavement support was also important in helping children/young people understand and cope with the reactions of their parents. The approach to sibling bereavement support was described as being child-centred and based on providing uplifting activities that also promoted open discussion of their sibling's death.

They did lots of lovely things, lots of activities and went out to different places and spoke about different things. It was a bit like a counselling group, but it wasn't where you just had to sit and talk, it was done in all other ways. (Interview Bereaved Parent 015)

It was nice that it wasn't always a down thing, they did stuff that was uplifting as well but it was things that made the kids think about their brother or sister. ... the kids could ask any questions they wanted ... it was stuff that was obviously on their mind and they wanted to know about. (Interview Bereaved Parent 008)

However, some bereaved parents felt that there was a need for more appropriate support for bereaved siblings in their mid to late teens.

\section{The nature of hospice support}

In the interviews hospice support was characterized by families in terms of its individualized and family-centred approach and the quality of the interpersonal relationships developed and this is supported by the survey data. A large majority $(83.3 \%$ to 95.6\%) rated the individualized, family-focused aspects of support highly (Table 5). Particularly highly rated aspects were the non-judgemental approach of staff and the individualized nature of care and support. Parents appreciated how the hospice focused on the whole family and not just the ill/disabled child and provided support that was flexible and based on their individual needs.

They take on the whole family not just the poorly child.

We are all important. (QN1-31)

The hospice was perceived as being accessible to parents when they needed their support which promoted their sense of coping and their feelings of security.

It is like an extended family or good friends that even though you don't see them often you know they are there if you need them. (Interview Bereaved Parent 008) 
Table 5. Views of parents on the nature of hospice support

\begin{tabular}{|c|c|c|c|c|c|}
\hline Aspect & $\begin{array}{l}\text { Strongly } \\
\text { agree (\%) }\end{array}$ & Agree (\%) & $\begin{array}{l}\text { Neither agree } \\
\text { nor disagree (\%) }\end{array}$ & Disagree (\%) & $\begin{array}{l}\text { Strongly } \\
\text { disagree (\%) }\end{array}$ \\
\hline \multicolumn{6}{|l|}{ Individualized and family-focused nature of support } \\
\hline $\begin{array}{l}\text { The support and care they provide to my child and family is based on our } \\
\text { individual needs }(n=70)\end{array}$ & $39(55.7)$ & $24(34.3)$ & $1(1.4)$ & $1(1.4)$ & $5(7.1)$ \\
\hline They recognize the demands of caring for my child $(n=69)$ & $38(55.1)$ & $22(31.9)$ & $6(8.7)$ & 0 & 0 \\
\hline They accept us as we are, without judging us $(n=68)$ & $38(55.9)$ & $27(39.7)$ & $1(1.5)$ & 0 & $2(2.9)$ \\
\hline They recognize the demands of caring for my child $(n=69)$ & $38(55.1)$ & $22(31.9)$ & $6(8.7)$ & 0 & 0 \\
\hline $\begin{array}{l}\text { The care they give respects the wishes of the young person as much as } \\
\text { possible }(n=70)\end{array}$ & $36(51.4)$ & $31(44.3)$ & 0 & 0 & $3(4.3)$ \\
\hline $\begin{array}{l}\text { They look at the needs of my child as a 'whole' (i.e. not just their physical } \\
\text { needs but their social and emotional needs as well; } n=68 \text { ) }\end{array}$ & $33(48.5)$ & $30(44.1)$ & $2(2.9)$ & $1(1.5)$ & $2(2.9)$ \\
\hline They take time to get to know me, my child and my family $(n=69)$ & $33(47.9)$ & $28(40.6)$ & $5(7.3)$ & $3(4.5)$ & 0 \\
\hline They are aware of my child's changing needs as s/he grows up $(n=67)$ & $32(47.8)$ & $25(37.3)$ & $5(7.5)$ & $5(7.5)$ & 0 \\
\hline They respect my child's usual routine $(n=67)$ & $29(43.3)$ & $32(47.8)$ & $1(1.5)$ & $2(3.0)$ & $3(4.5)$ \\
\hline Our customs, values and spiritual beliefs are respected $(n=66)$ & $27(40.9)$ & $28(42.4)$ & $5(7.6)$ & 0 & $6(9.1)$ \\
\hline \multicolumn{6}{|l|}{ Parental involvement and recognition of parental expertise } \\
\hline $\begin{array}{l}\text { They listen to what I have to say about my child's and family's } \\
\text { needs }(n=68)\end{array}$ & $45(64.3)$ & $18(25.7)$ & $4(5.7)$ & $1(1.4)$ & 0 \\
\hline $\begin{array}{l}\text { They recognize that I have the final say when making any } \\
\text { decisions }(n=67)\end{array}$ & $39(58.2)$ & $25(37.3)$ & $2(3.0)$ & $1(1.5)$ & 0 \\
\hline $\begin{array}{l}\text { They give me the chance to say what is important to me about how my } \\
\text { child is looked after }(n=65)\end{array}$ & $39(60.0)$ & $20(30.8)$ & $3(4.6)$ & 0 & $3(4.6)$ \\
\hline They trust me as the expert about my child and their needs $(n=68)$ & $37(54.4)$ & $27(39.7)$ & $1(1.5)$ & $1(1.5)$ & $2(2.9)$ \\
\hline \multicolumn{6}{|l|}{ Quality of interpersonal relationships } \\
\hline They show sensitivity to my feelings and worries $(n=71)$ & $46(64.8)$ & $17(23.9)$ & $4(5.6)$ & $2(2.8)$ & $2(2.8)$ \\
\hline They have a caring approach to me, my child and family $(n=68)$ & $44(64.7)$ & $20(29.4)$ & $2(2.9)$ & 0 & $2(2.9)$ \\
\hline I feel able to talk to the staff $(n=69)$ & $42(60.9)$ & $17(24.6)$ & $6(8.7)$ & $2(2.9)$ & $2(2.9)$ \\
\hline Our confidentiality and privacy is respected $(n=69)$ & $37(53.6)$ & $21(30.4)$ & $3(4.4)$ & $3(4.4)$ & $5(7.3)$ \\
\hline The staff stimulate children who can't communicate $(n=65)$ & $36(55.4)$ & $19(29.2)$ & $4(6.2)$ & $2(3.1)$ & $4(6.2)$ \\
\hline They make sure that everyone knows what my child's skills are $(n=67)$ & $32(47.8)$ & $27(40.3)$ & $5(7.5)$ & $3(4.5)$ & 0 \\
\hline $\begin{array}{l}\text { They plan together to make sure everyone does the same thing when } \\
\text { caring for my child }(n=67)\end{array}$ & $29(43.3)$ & $28(41.8)$ & $6(9.0)$ & $2(3.0)$ & $2(3.0)$ \\
\hline $\begin{array}{l}\text { They make sure that my child is looked after by someone that they } \\
\text { know }(n=69)\end{array}$ & $28(40.6)$ & $26(37.7)$ & $9(13.0)$ & $2(2.9)$ & $4(5.8)$ \\
\hline A named member of staff is responsible for my child $(n=67)$ & $26(38.8)$ & $35(52.2)$ & $3(4.5)$ & $1(1.5)$ & $2(3.0)$ \\
\hline
\end{tabular}

Interpersonal relationships with hospice staff were highly rated (Table 5), in particular, their caring and nonjudgemental approach. The relationships developed with staff enabled parents to feel able to talk to them about their feelings and parents felt nurtured during their visits as a result of the emotional care and practical support received. They also valued how staff listened to parents' wishes about their child's care and saw the importance of understanding their individual routines and needs. Parental involvement in decision making and the recognition of parental expertise was highly rated in the survey (90\% to $95.5 \%$; Table 5 ). The relationships and rapport that staff had developed with their children was important to parents. However, a small number of parents were concerned that staff could become 'burnt out' because of the emotionally difficult nature of their work and as a result become detached.
Young people reported positive relationships with staff and felt their views were listened and responded to. They felt comfortable talking to them about their feelings and concerns although a small number were concerned about confidentiality and were unsure if staff would disclose the content of conversations to parents or other members of staff.

\section{Discussion}

This study has a number of limitations that need to be taken into account. The generalizability of the findings is limited by it having been conducted at a single hospice and there is a possibility that non-responders to the survey were a less satisfied group of parents or had different socio-demographic characteristics to the study sample. It would have been useful to examine 
differences between responders and non-responders but because of research governance issues that was not possible.

In common with other studies the hospice was seen as a 'lifeline' for parents, providing them with a much needed break from caring (Stein et al. 1989; Robinson \& Jackson 1999; Hunt et al. 2003). Other research has identified that having a break from caring is one of most frequently reported needs of parents with a disabled child (Beresford 1995; Hoare et al. 1998). Obtaining such a break is often problematic where children have specialized healthcare needs (Kirk 1999; Robinson et al. 2001; Heaton et al. 2003; Kirk \& Glendinning 2004) and hospices are one of the few places with the expertise to care for this group of children. However, this study highlights that parents feel they need more of this type of support from hospices. Indeed, demand on hospices is likely to increase given the increasing numbers of children with lifelimiting conditions and complex needs (Sloper \& Beresford 2006).

Parents reported high levels of satisfaction with the quality of support provided, in particular, the clinical and interpersonal skills of the staff, their involvement in decision making and the individualized and family-focused approach to support. However, it was apparent that families' sense of gratitude could be a barrier to raising issues of concern with staff. This could be in relation to requesting additional support or discussing their concerns about the quality of their child's care. Hospices need to be aware of this and develop processes and support for parents and young people to discuss areas of dissatisfaction and unmet need. Bereavement support appeared to be not meeting the needs of fathers and older siblings.

For young people hospices provided an opportunity to meet other young people, take part in different activities, spend time with friends and develop their independence. While other research has questioned the appropriateness for young people of combining short-term care alongside end-of-life care (While et al. 1996; Morris 1998), this study suggests that hospices may enable the development of friendships and peer support among young people experiencing similar shortened life expectancies. A consistent theme in relation to support for young people and siblings was the need to develop facilities, activities and bereavement support specifically for teenagers/young people. This need may reflect that hospices were developed originally in response to the needs of younger children but increasing life expectancy now means that they are supporting a greater age range of children/young people. The challenge facing hospices now therefore is to determine how to respond to increasing need and a changing population of users.

\section{Conclusion}

Children's hospices are an important part of palliative care provision, yet the support they provide for families has been under-researched. This exploratory study has aimed to address this gap in knowledge and provide insight into elements of support that work well as well as identifying aspects that need improvement. It has highlighted that families value the model of care provided but that they have unmet needs in terms of the quantity of support offered. In addition, the study has suggested that the specific needs of teenagers/young people with life-limiting conditions, bereaved fathers and bereaved older siblings may not be being met by hospices. Further research is needed to examine the particular needs of these groups in order to develop appropriate support.

\section{Key messages}

- Parents value a model of hospice support that provides holistic, family-centred care that is responsive to individual needs and which promotes control and active involvement in decision making.

- Providing a break from caring is an important way in which hospices support parents but parents report unmet needs in this area and want more of this form of support.

- For young people hospices provide an opportunity to meet other young people and to take part in activities. However, young people would like greater access to age-appropriate activities and facilities.

- Parents are highly satisfied with the quality of care provided although their feelings of gratitude and the good relationships they develop with staff can create barriers to raising concerns.

- Hospices need to respond to increasing demand and a changing population and develop their facilities and activities to meet the needs of a changing population. In addition, it appears that the needs of bereaved fathers and older siblings need addressing.

\section{Acknowledgements}

The researchers would like to thank the parents and young people for sharing their views and experiences with the researchers. We would also like to thank the hospice staff for assisting us with this study.

(c) 2011 Blackwell Publishing Ltd, Child: care, health and development, 38, 1, 32-40 


\section{References}

Beresford, B. (1995) Expert Opinions: A National Survey of Parents Caring for a Severely Disabled Child. Policy Press, Bristol, UK.

Davies, B., Collins, J., Steele, R., Cook, K., Brenner, A. \& Smith, S. (2005) Children's perspectives on a pediatric hospice program. Journal of Palliative Care, 21, 252-261.

Department of Health (2008) Better Care: Better Lives: Improving Outcomes and Experiences for Children, Young People and Their Families Living with Life-Limiting and Life-Threatening Conditions. Department of Health, London, UK.

Emond, A. \& Eaton, N. (2004) Supporting children with complex healthcare needs and their families: an overview of the research agenda. Child: Care, Health and Development, 30, 195-199.

Greco, V., Sloper, P., Webb, R. \& Beacham, J. (2005) An Exploration of Different Models of Multi-Agency Partnerships in Key Worker Services for Disabled Children: Effectiveness and Costs. Department for Education and Skills, London, UK.

Heaton, J., Noyes, J., Sloper, P. \& Shah, R. (2003) Technology-dependent children and family life. Research Works 2003-02. SPRU, University of York, York, UK.

Hoare, P., Harris, M., Jackson, P. \& Kerley, S. (1998) A community survey of children with severe intellectual disability and their families: psychological adjustment, carer distress and the effect of respite care. Journal of Intellectual Disability Research, 42, 218-227.

Hunt, A., Elston, S. \& Galloway, J. (2003) Voices for Change. Current Perception of Services for Children With Palliative Care Needs and Their Families. ACT, Bristol, UK.

King, S., Rosenbaum, P. \& King, G. (1995) The Measure of Processes of Care: A Means to Assess the Family-Centered Behaviours of Health Care Providers. McMaster University, Hamilton, ON, Canada.

Kirk, S. (1999) Caring for children with specialised health care needs in the community: the challenges for primary care. Health \& Social Care in the Community, 7, 350-357.
Kirk, S. \& Glendinning, C. (2004) Developing services to support parents caring for a technology-dependent child at home. Child: Health, Care and Development, 30, 209-218.

Middleton, L. (1998) Consumer satisfaction with services for disabled children. Journal of Interprofessional Care, 12, 223-231.

Morris, J. (1998) Don't Leave Us Out: Involving Disabled Children and Young People With Communication Impairments. Joseph Rowntree Foundation, York, UK.

Ritchie, J. \& Lewis, J. (2003) Qualitative Research Practice: A Guide for Social Science Students and Researchers. Sage, London, UK.

Robinson, C. \& Jackson, P. (1999) The role of children's hospices in providing respite care. Joseph Rowntree Foundation Findings. Joseph Rowntree Foundation, York, UK.

Robinson, C., Jackson, P. \& Townsley, R. (2001) Short breaks for families caring for a disabled child with complex health needs. Child \& Family Social Work, 6, 67-75.

Sloper, P. (1999) Models of service support for parents of disabled children. What do we know? What do we need to know? Child: Care, Health and Development, 25, 85-99.

Sloper, P. \& Beresford, B. (2006) Families with disabled children. British Medical Journal, 333, 928-929.

Sloper, P. \& Turner, S. (1992) Service needs of families of children with severe disability. Child: Care, Health and Development, 18, 250-282.

Steele, R., Davies, B., Collins, J. \& Cook, K. (2005) End-of-life care in a children's hospice program. Journal of Palliative Care, 21, 5-11.

Stein, A., Forrest, G. C., Woolley, H. \& Baum, J. D. (1989) Life threatening illness and hospice care. Archives of Disease in Childhood, 64, 697-702.

While, A., Citrone, C. \& Cornish, J. (1996) A Study of the Needs and Provisions for Families Caring for Children With Life-Limiting Incurable Disorders. Kings College, London, UK. 